\title{
Ischemic Preconditioning Fails to Confer Additional Protection Against Ischemia-Reperfusion Injury in the Hypothyroid Rat Heart
}

\author{
I. MOUROUZIS, A. DIMOPOULOS, T. SARANTEAS, N. TSINARAKIS, E. LIVADAROU, \\ D. SPANOU, A. D. KOKKINOS, C. XINARIS, C. PANTOS, D. V. COKKINOS ${ }^{1}$
}

\author{
Department of Pharmacology, University of Athens and ${ }^{1}$ First Cardiology Department, Onassis \\ Cardiac Surgery Center, Athens, Greece
}

Received August 31, 2007

Accepted November 11, 2007

On-line January 17, 2008

\begin{abstract}
Summary
There is accumulating evidence showing that ischemic preconditioning $(\mathrm{PC})$ may lose its cardioprotective effect in the diseased states. The present study investigated whether PC can be effective in hypothyroidism, a clinical condition which is common and often accompanies cardiac diseases such as heart failure and myocardial infarction. Hypothyroidism was induced in rats by 3-week administration of 6n-propyl-2-thiouracil in water $(0.05 \%)$. Normal and hypothyroid hearts (HYPO) were perfused in Langendorff mode and subjected to $20 \mathrm{~min}$ of zero-flow global ischemia and $45 \mathrm{~min}$ of reperfusion. A preconditioning protocol (PC) was also applied prior to ischemia. HYPO hearts had significantly improved post-ischemic recovery of left ventricular developed pressure, end-diastolic pressure and reduced lactate dehydrogenase release. Furthermore, phospho-JNK and p38 MAPK levels after ischemia and reperfusion were 4.0 and 3.0 fold lower in HYPO as compared to normal hearts $(P<0.05)$. A different response to $\mathrm{PC}$ was observed in normal than in HYPO hearts. PC improved the post-ischemic recovery of function and reduced the extent of injury in normal hearts but had no additional effect on the hypothyroid hearts. This response, in the preconditioned normal hearts, resulted in 2.5 and 1.8 fold smaller expression of the phospho-JNK and phospho-p38 MAPK levels at the end of reperfusion, as compared to non-PC hearts $(P<0.05)$, while in HYPO hearts, no additional reduction in the phosphorylation of these kinases was observed after PC. Hypothyroid hearts appear to be tolerant to ischemia-reperfusion injury. This response may be, at least in part, due to the downregulation of ischemia-reperfusion induced activation of JNKs and p38 MAPK kinases. PC is not associated with further reduction in the activation of these kinases in the hypothyroid hearts and fails to confer added protection in those hearts.
\end{abstract}

\section{Key words}

Thyroid hormone • Myocardial ischemia • Ischemic preconditioning • Hypothyroidism • JNKs • p38 MAPK

\section{Corresponding author}

Constantinos Pantos, Department of Pharmacology, University of Athens, 75 Mikras Asias Ave., 11527 Goudi, Athens, Greece. Fax: (+30210) 7462560. E-mail:cpantos@cc.uoa.gr

\section{Introduction}

Over the past years, research has substantially contributed to better understanding of the response of the myocardium to ischemic injury. It is now recognized that hearts can be adapted to ischemic stress by interventions such as ischemic preconditioning or heat stress (Das and Maulik 2006, Koneru et al. 2007, Valen 2003, Pantos et al. 2003a). It has been suggested that preconditioning mechanisms could be therapeutically exploitable. However, most of the research on preconditioning has focused on the "non-diseased" myocardium and little is known whether this phenomenon can be applied in the pathological myocardium (Pantos et al. 2007a). Since coronary artery disease frequently co-exists with other morbidities, it is conceivable that this issue merits further research before preconditioning can be clinically exploited.

Thyroid hormones are considered to have a critical role in myocardial ischemia and cardiac remodeling. In fact, changes in thyroid hormones, $\mathrm{T}_{4}$ and $\mathrm{T}_{3}$, may be associated with altered response of the myocardium to ischemia (Pantos et al. 2003b, 2004, 2006). Furthermore, hypothyroid-like changes are observed in the 
post-infarcted myocardium (Pantos et al. 2005a) and low $\mathrm{T}_{3}$ levels are common in patients with heart failure or myocardial infarction and are associated with increased mortality and morbidity (Friberg et al. 2002, Iervasi et al. 2003, Pantos et al. 2007c). Thus, the question whether cardioprotective interventions, such as ischemic preconditioning, can also be operable under hypothyroid states may be of clinical and therapeutic importance.

The present study investigated the response of the hypothyroid heart to ischemic preconditioning in an experimental model of propylthiouracil-induced hypothyroidism in rats.

\section{Methods}

\section{Animals}

Thirty nine rats, $290-350 \mathrm{~g}$ were used for this study. Male Wistar rats were used as we have done in previous studies (Pantos et al. 1999, 2003a,b,c,d, 2005b, 2006) The rats were handled in accordance with the Guide for the Care and Use of Laboratory Animals published by the US National Institutes of Health (NIH Pub. No. 8323, Revised 1996).

\section{Experimental hypothyroidism}

Hypothyroidism was induced in rats by 3 -week administration of 6n-propyl-2-thiouracil in drinking water to a final concentration of $0.05 \%$. We have previously shown that this model results in moderate decrease in $\mathrm{T}_{4}$ and $\mathrm{T}_{3}$ levels in plasma (Pantos et al. 2003b, 2005b). These animals were designated as HYPO. Untreated rats were used as controls and were designated as NORM.

\section{Echocardiography}

Rats were sedated with ketamine hydrochloride $(100 \mathrm{mg} / \mathrm{kg}$ ) and heart function was evaluated by echocardiography. Short- and long-axis images were acquired using a digital ultrasound system (Sonosite 180Plus, 21919 30th Drive SE, Bothell, WA, USA) with a $7.0 \mathrm{MHz}$ sector-array probe, as previously described (Pantos et al. 2007b,d). Ejection fraction, left ventricular internal diameter at diastolic phase (LVIDd), LV internal diameter at systolic phase (LVIDs), posterior wall thickness at diastolic phase (LVPW) and posterior wall velocity of shortening (PWV) were measured. All measurements were averaged for at least three consecutive cardiac cycles.

\section{Isolated heart preparation}

A non-working isolated rat heart preparation was perfused at a constant flow according to the Langendorff technique. An intraventricular balloon allowed measurement of contractility under isovolumic conditions. Left ventricular balloon volume was adjusted to produce an average initial left ventricular end-diastolic pressure of 6-7 $\mathrm{mm} \mathrm{Hg}$ in all groups and was held constant thereafter throughout the experiment. Since the balloon was not compressible, left ventricular contraction was isovolumic. As intraventricular volume was maintained at a constant value, diastolic fiber length, which represented preload, did not change. Thus, the left ventricular peak systolic pressure and the left ventricular developed pressure (LVDP), defined as the difference between left ventricular peak systolic pressure and left ventricular end-diastolic pressure, represented contractility indexes obtained under isometric conditions.

Rats were anesthetized with ketamine $\mathrm{HCl}$ and heparin 1000 IU was given intravenously before thoracotomy. The hearts were rapidly excised, placed in ice-cold Krebs-Henseleit buffer (composition in $\mathrm{mmol} / \mathrm{l}$ : sodium chloride 118 , potassium chloride 4.7 , potassium phosphate monobasic 1.2 , magnesium sulfate 1.2 , calcium chloride 1.4 , sodium bicarbonate 25 , and glucose 11 ) and mounted on the aortic cannula of the Langendorff perfusion system. Perfusion with oxygenated $\left(95 \% \mathrm{O}_{2} / 5\right.$ $\% \mathrm{CO}_{2}$ ) Krebs-Henseleit buffer was established within $60 \mathrm{~s}$ after thoracotomy. Flow rate was approximately $16 \mathrm{ml} / \mathrm{min}$ per gram of LV weight in both NORM and HYPO hearts in order to obtain a mean perfusion pressure of $70 \mathrm{~mm} \mathrm{Hg}$. The perfusion apparatus was heated to ensure a temperature of $37{ }^{\circ} \mathrm{C}$ throughout the course of the experiment. In our experimental design sinus node was removed and hearts were paced at 320 beats/min with a Harvard pacemaker. The pacemaker was turned off during ischemia. The water filled balloon, connected to a pressure transducer and coupled to a Gould RS 3400 recorder was advanced into the left ventricle through an incision in the left atrium. Pressure signal was transferred to a computer using a data analysis software (IOX, Emka Technologies) which allowed continuous monitoring and recording of heart function (Pantos et al. 2003d, 2005a, 2006, 2007b). All preparations included in this study were stable for at least the last $10 \mathrm{~min}$ of the stabilization period. Isolated hearts without stable measurements of LVDP, LV enddiastolic pressure and perfusion pressure for the last $10 \mathrm{~min}$ of the stabilization period or those presented severe reperfusion arrhythmias were excluded from the analysis. 


\section{Experimental protocol}

Hearts from HYPO and NORM rats were excised and rinsed in Krebs buffer. The left ventricle was isolated, frozen in liquid nitrogen and used for measurements of baseline myocardial protein expression (myosin heavy chain isoforms and SERCA) (NORMbase, $n=5$ and HYPO-base, $n=5$ ).

NORM and HYPO rats were anesthetized and subjected to echocardiography analysis. Hearts were removed, isolated and perfused in a Langendorff preparation. Isolated hearts were subjected to $20 \mathrm{~min}$ of stabilization, $20 \mathrm{~min}$ of zero-flow global ischemia and $45 \mathrm{~min}$ of reperfusion (NORM(I/R), n=7, HYPO(I/R), $\mathrm{n}=9$ ). Additional hearts were subjected to preconditioning protocol before the index ischemia, NORM-PC(I/R), $n=6$, HYPO-PC(I/R), $n=7$. The preconditioning protocol consisted of one cycle of $3 \mathrm{~min}$ ischemia $/ 5 \mathrm{~min}$ reperfusion and three repeated cycles of $5 \mathrm{~min}$ ischemia/ 5 min reperfusion.

Since hypothyroid rat heart is highly protected and this could have masked the preconditioning effect, we also performed experiments extending the period of ischemia to $30 \mathrm{~min}$ in hypothyroid hearts to reach the extent of post-ischemic damage seen with less ischemia in normal hearts. Thus, preconditioned and nonpreconditioned hypothyroid hearts were subjected to $30 \mathrm{~min}$ of zero-flow global ischemia and $45 \mathrm{~min}$ of reperfusion (HYPO(30I/R), $n=6, \quad$ HYPO-PC(30I/R), $n=6)$. At the end of the experimental protocol the left ventricle was isolated, frozen in liquid nitrogen and used for determination of p38 MAPK and JNK activation.

\section{Measurement of mechanical function}

Left ventricular systolic function was assessed by recording the left ventricular developed pressure which was measured at the end of the stabilization period (LVDP, $\mathrm{mm} \mathrm{Hg}$ ) and after $45 \mathrm{~min}$ of reperfusion (LVDP45). LVDP and $+\mathrm{dp} / \mathrm{dt} \quad(\mathrm{mm} \mathrm{Hg} / \mathrm{s}),-\mathrm{dp} / \mathrm{dt}$ $(\mathrm{mm} \mathrm{Hg} / \mathrm{s})$ were used to assess baseline myocardial function. Post-ischemic myocardial function was assessed by the recovery of LVDP and expressed as \% of the baseline value (LVDP \%). Diastolic function was assessed by monitoring isovolumic left ventricular enddiastolic pressure (LVEDP, $\mathrm{mm} \mathrm{Hg}$ ) as a measure of diastolic chamber distensibility. Left ventricular enddiastolic pressure was measured after $45 \mathrm{~min}$ of reperfusion (LVEDP45).
Protein isolation, sodium dodecyl sulfate-protein polyacrylamide (SDS-PAGE) gel electrophoresis and immunodetection

Determination of protein expression was performed as previously described (Pantos et al. 2003d, $2005 a, b)$. Left ventricular tissue was homogenized in icecold buffer containing $10 \mathrm{mM}$ Tris- $\mathrm{HCl} \mathrm{pH}$ 7.5, $3 \mathrm{mM}$ EDTA, $1 \mathrm{mM}$ phenylmethanesulphonyl fluoride, $30 \mu \mathrm{M}$ leupeptin, $1 \mathrm{mM} \mathrm{Na} \mathrm{VO}_{4}$ and Triton X100 0.1\% with a Polytron homogenizer. The resulting homogenate was centrifuged at $10000 \mathrm{~g}$ for $10 \mathrm{~min}$ at $4{ }^{\circ} \mathrm{C}$. The supernatant (Triton-soluble) corresponded to the cytosolmembrane fraction and was kept at $-80{ }^{\circ} \mathrm{C}$ for further processing. Protein concentrations were determined by the bicinchoninic acid (BCA) method, using bovine serum albumin as a standard.

Samples were prepared for sodium dodecyl sulfate polyacrylamide gel electrophoresis (SDS-PAGE) by boiling for $5 \mathrm{~min}$ in Laemmli sample buffer containing $5 \%$ 2-mercaptoethanol. Aliquots $(40 \mu \mathrm{g})$ were loaded onto $7.5 \%$ or $9 \%(\mathrm{w} / \mathrm{v})$ acrylamide gels and subjected to SDS-PAGE in a Bio-Rad Mini Protean gel apparatus. Following SDS-PAGE, proteins were transferred electrophoretically to a nitrocellulose membrane (Hybond ECL) at $100 \mathrm{~V}$ and $4{ }^{\circ} \mathrm{C}$, for $1.5 \mathrm{~h}$ using Towbin buffer for Western blotting analysis. Subsequently, filters were probed with specific antibodies against SERCA (Affinity Bioreagents, MA3-919, dilution 1:1000), total p38 MAPK, dual phospho-p38 MAPK, total c-jun NH2terminal kinases (JNKs), dual phospho-JNKs, (Cell Signaling Technology, dilution 1:1000) overnight at $4{ }^{\circ} \mathrm{C}$ and immunoreactivity was detected by enhanced chemiluminescence. For comparisons between groups, five samples from each group were loaded on the same gel. Ponceau staining was used in each filter in order to normalize slight variations in total protein loading. Immunoblots and gels were quantified using the AlphaScan Imaging Densitometer (Alpha Innotech Corporation, 14743, Catalina Street, San Leandro, CA).

\section{Measurement of myosin heavy chain isoform content}

Homogenates of all samples were diluted 40 fold with Laemmli sample buffer containing $5 \%$ 2-mercaptoethanol. The composition and preparation of the gels was carried out as previously described (Pantos et al. 2005b, Reiser and Kline 1998). Briefly, the stacking and separating gels consisted of 4 and $8 \%$ acrylamide (wt/vol) respectively, with Acryl:bis-Acryl in the ratio of 50:1. The stacking and separating gels included $5 \%$ 
(vol/vol) glycerol. The upper running buffer consisted of $0.1 \mathrm{M}$ Tris (base), $150 \mathrm{mM}$ glycine, $0.1 \%$ sodium dodecyl sulfate (SDS) and 2-mercaptoethanol at a final concentration of $10 \mathrm{mM}$. The lower running buffer consisted of $0.05 \mathrm{M}$ Tris (base), $75 \mathrm{mM}$ glycine and 0.05 $\%$ SDS. The gels were run in Biorad Protean II xi electrophoresis unit at a constant voltage of $240 \mathrm{~V}$ for $21 \mathrm{~h}$ at $8{ }^{\circ} \mathrm{C}$. The gels were fixed and silver-stained (Biorad silver stain kit). Gels were scanned and quantified using the AlphaScan Imaging Densitometer (Alpha Innotech Corporation, USA).

\section{Measurement of lactate dehydrogenase $(L D H)$ release}

Coronary effluent was collected during $45 \mathrm{~min}$ of reperfusion and was used for the measurement of lactate dehydrogenase (LDH) activity in IU/L spectrophotometrically (LDH UV Fluid, Rolf Greiner Biochemica). LDH release was expressed per gram of tissue and was used as an index of myocardial injury.

\section{Measurement of thyroid hormones}

Plasma L-thyroxine and 3,5,3' tri-iodothyronine quantitative measurements were performed with ELISA, using kits obtained from Alpha Diagnostic International, Texas, USA (No 1100 for total $\mathrm{T}_{4}$ and No 1700 for total $\mathrm{T}_{3}$ ), as previously described (Pantos et al. 2005a, 2007d). L-thyroxine and 3,5,3'-triiodothyronine levels were expressed as $\mathrm{nmol} / \mathrm{L}$ of plasma. Absorbance measurements were performed at $450 \mathrm{~nm}$ with Tecan Genios ELISA reader (Tecan, Austria).

\section{Statistics}

Values are presented as mean \pm S.E.M. Unpaired t-test and Mann-Whitney test were used for differences between 2 groups. One-way analysis of variance with Bonferroni or Dunnett's correction was used when multiple comparisons were carried out. A two-tailed test with a $\mathrm{P}$ value less than 0.05 was considered significant.

\section{Results}

\section{Animal characteristics}

Body weight change and left ventricular weight were $+25 \pm 4 \mathrm{~g}$ and $740 \pm 31 \mathrm{mg}$ for NORM vs. $-18 \pm 3 \mathrm{~g}$ and $585 \pm 20 \mathrm{mg}$ for HYPO $(\mathrm{P}<0.05)$. Spontaneous heart rate determined during echocardiography analysis was $386 \pm 12 \mathrm{bpm}$ for NORM and $264 \pm 17 \mathrm{bpm}$ for HYPO rats $(\mathrm{P}<0.05) . \mathrm{T}_{4}$ and $\mathrm{T}_{3}$ levels (in $\mathrm{nM}$ ) were found to be

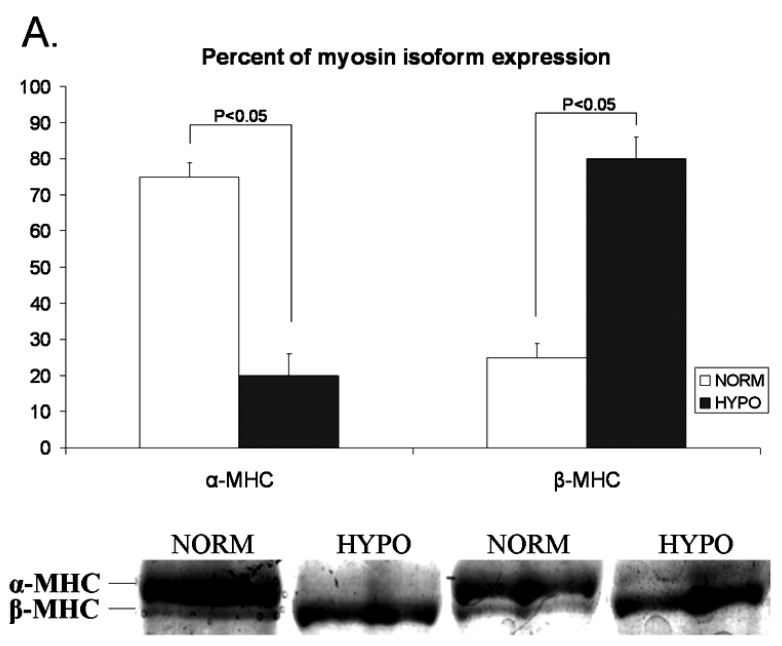

B. SERCA Expression
(Arbitrary Units)
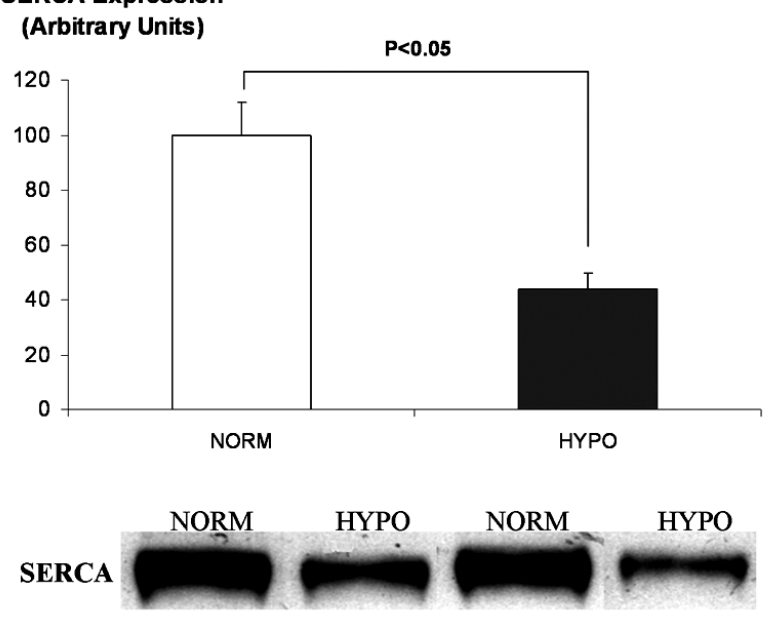

Fig. 1. Densitometric assessment in arbitrary units and representative images of $a$ and $\beta$ isoforms of myosin heavy chain (A) and SERCA protein expression (B) in normal (NORM-base) and hypothyroid hearts (HYPO-base, $n=5$ ).

$47.3 \pm 2.1$ and $0.98 \pm 0.07$ for NORM vs. $19.6 \pm 0.4$ and $0.23 \pm 0.05$ for HYPO $(\mathrm{P}<0.05)$.

\section{SERCA and myosin isoform expression}

A shift from $\alpha$ to $\beta$ myosin isoform expression was found in HYPO-base as compared to NORM-base hearts. In fact, HYPO-base hearts expressed $20 \%$ $\alpha$-MHC and $80 \% \beta$-MHC as compared to $75 \% \alpha-\mathrm{MHC}$ and $25 \% \quad \beta$-MHC in NORM-base hearts $(\mathrm{P}<0.05)$ (Fig. 1A). In addition, SERCA expression was found to be 2.5 fold smaller in HYPO-base than in NORM-base hearts $(\mathrm{P}<0.05)$ (Fig. 1B).

\section{Parameters of cardiac function at baseline}

Data of contractile function are summarized in 
Table 1. Parameters of cardiac function at baseline

\begin{tabular}{lll}
\hline & NORM & HYPO \\
\hline LVIDd $(\mathrm{mm})$ & $6.6 \pm 0.1$ & $6.4 \pm 0.1$ \\
LVIDs $(\mathrm{mm})$ & $4.0 \pm 0.2$ & $4.9 \pm 0.3^{*}$ \\
LVPW $(\mathrm{mm})$ & $1.9 \pm 0.03$ & $1.7 \pm 0.07^{*}$ \\
$P W V(\mathrm{~mm} / \mathrm{s})$ & $35.4 \pm 3.5$ & $16.5 \pm 1.5^{*}$ \\
$E F \%$ & $71.5 \pm 2.7$ & $56.0 \pm 4.2^{*}$ \\
$L V D P(\mathrm{~mm} \mathrm{Hg})$ & $115.2 \pm 3.5$ & $93.8 \pm 2.1^{*}$ \\
$+d p / d t(\mathrm{~mm} \mathrm{Hg} / \mathrm{s})$ & $3900 \pm 117$ & $2400 \pm 107^{*}$ \\
$-d p / d t(\mathrm{~mm} \mathrm{Hg} / \mathrm{s})$ & $2200 \pm 54$ & $1800 \pm 53^{*}$ \\
\hline
\end{tabular}

Left ventricular internal diameter at diastolic phase (LVIDd) and at systolic phase (LVIDs), posterior wall thickness at diastolic phase (LVPW), posterior wall velocity of shortening (PWV), ejection fraction, left ventricular developed pressure (LVDP) and the positive and negative first derivative of LVDP (+dp/dt and $-\mathrm{dp} / \mathrm{dt}$ ) are shown in this table. The values are mean \pm S.E.M. $* \mathrm{P}<0.05$ vs. NORM

Table 2. Indices of recovery after ischemia-reperfusion

\begin{tabular}{lccc}
\hline & LVDP\% & $\begin{array}{c}\text { LVEDP45 } \\
(\mathbf{m m ~ H g})\end{array}$ & LDH (IU/g) \\
& & & \\
\hline NORM $(I / R)$ & $58.7 \pm 6.3$ & $56.5 \pm 6.8$ & $8.5 \pm 0.4$ \\
NORM-PC(I/R) & $81.4 \pm 3.8^{*}$ & $20.3 \pm 5.0^{*}$ & $5.8 \pm 0.8^{*}$ \\
HYPO $(I / R)$ & $93.6 \pm 3.9^{*}$ & $9.2 \pm 1.8^{*}$ & $4.0 \pm 0.3^{*}$ \\
HYPO-PC(I/R) & $88.0 \pm 3.9^{*}$ & $13.5 \pm 2.6^{*}$ & $5.7 \pm 1.1^{*}$ \\
\hline
\end{tabular}

LVDP at the end of reperfusion expressed as $\%$ of the baseline value (LVDP\%), Left ventricular end-diastolic pressure after $45 \mathrm{~min}$ of reperfusion (LVEDP45) and LDH release expressed per gram of tissue are shown in this table. The values are mean (S.E.M). $* \mathrm{P}<0.05$ vs. NORM(I/R)

Table 1. Basal contractile function was significantly reduced in HYPO hearts. Ejection fraction and posterior wall velocity of shortening (PWV) measured by ultrasonography in vivo and LVDP and $+/-\mathrm{dp} / \mathrm{dt}$ measured under isometric conditions were shown to be significantly decreased in HYPO hearts.

Parameters of post-ischemic myocardial function and $L D H$ release

NORM-PC(I/R) and HYPO(I/R) hearts showed significantly improved recovery of function, attenuated diastolic dysfunction and reduced $\mathrm{LDH}$ release as compared to NORM(I/R) hearts (Table 2). However, post-ischemic myocardial function and $\mathrm{LDH}$ release were not different between $\mathrm{HYPO}(\mathrm{I} / \mathrm{R})$ and $\mathrm{HYPO}-\mathrm{PC}(\mathrm{I} / \mathrm{R})$
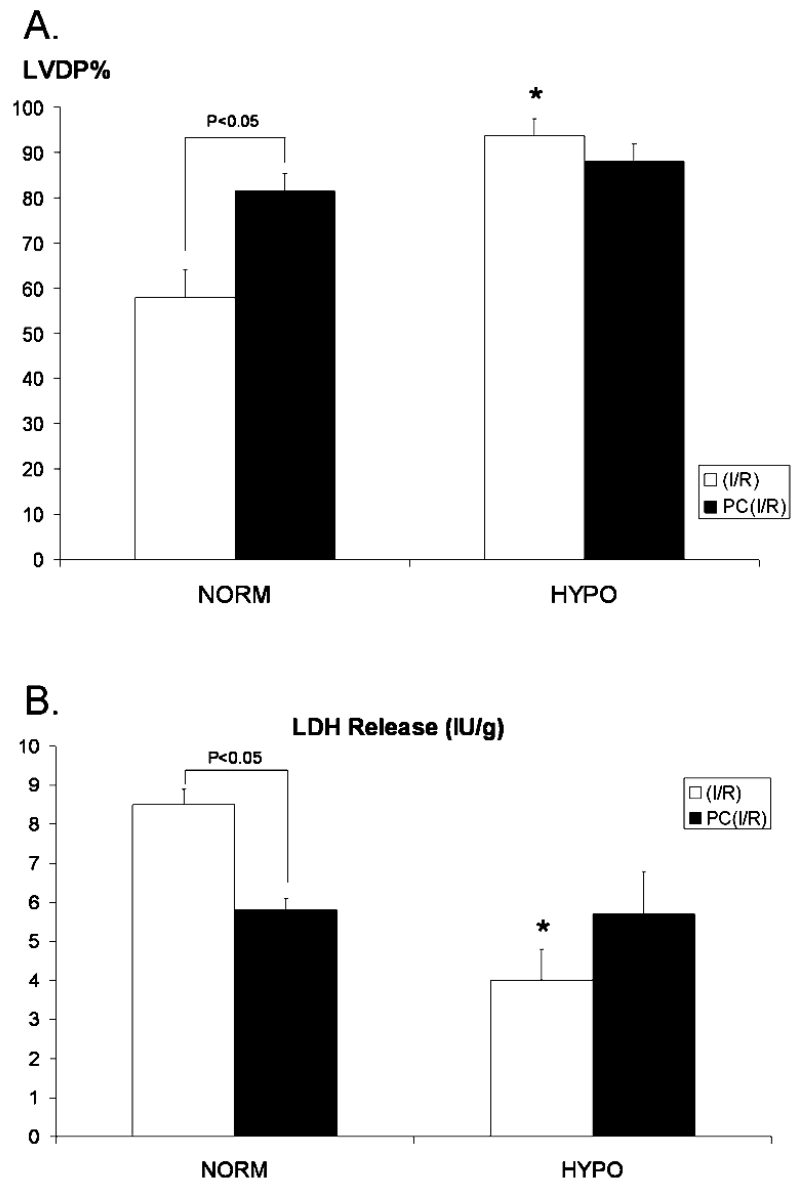

Fig. 2. Recovery of left ventricular developed pressure (LVDP\%, A) and $L D H$ release (B) in normal [NORM(I/R)], normal preconditioned [NORM-PC(I/R)], hypothyroid $[\mathrm{HYPO}(\mathrm{I} / \mathrm{R})]$ and hypothyroid preconditioned hearts [HYPO-PC(I/R)] subjected to 20 min of ischemia and 45 min of reperfusion. $* \mathrm{P}<0.05$ vs. $\operatorname{NORM}(\mathrm{I} / \mathrm{R})$

hearts (Table 2, Fig. 2).

Extending the period of ischemia to $30 \mathrm{~min}$, LVDP \% and LDH were $69.3 \pm 10.4$ and $12.9 \pm 2.3$ for HYPO(30I/R) vs. $59.5 \pm 10.8$ and $16.2 \pm 4.9$ for HYPO$\mathrm{PC}(30 \mathrm{I} / \mathrm{R})(\mathrm{P}>0.05)$. In addition, LVEDP45 was $21 \pm 5.1$ for $\operatorname{HYPO}(30 \mathrm{I} / \mathrm{R})$ vs. $22.8 \pm 4.9$ for $\operatorname{HYPO}-\mathrm{PC}(30 \mathrm{I} / \mathrm{R})$ $(\mathrm{P}>0.05)$.

Ischemia-reperfusion induced activation of the proapoptotic kinases p38 MAPK and JNK

In normal hearts, ischemic preconditioning resulted in reduced expression of the phosphorylated p54 JNK and p38 MAPK levels by 2.5 fold and 1.8 fold, respectively $(\mathrm{P}<0.05)$. In the hypothyroid hearts, phosphorylated p54 JNK and p38 MAPK were 4.0 fold and 3.0 less as compared to normal hearts $(\mathrm{P}<0.05)$, but no further reduction in the expression levels of these phosphorylated kinases was observed in hypothyroid 

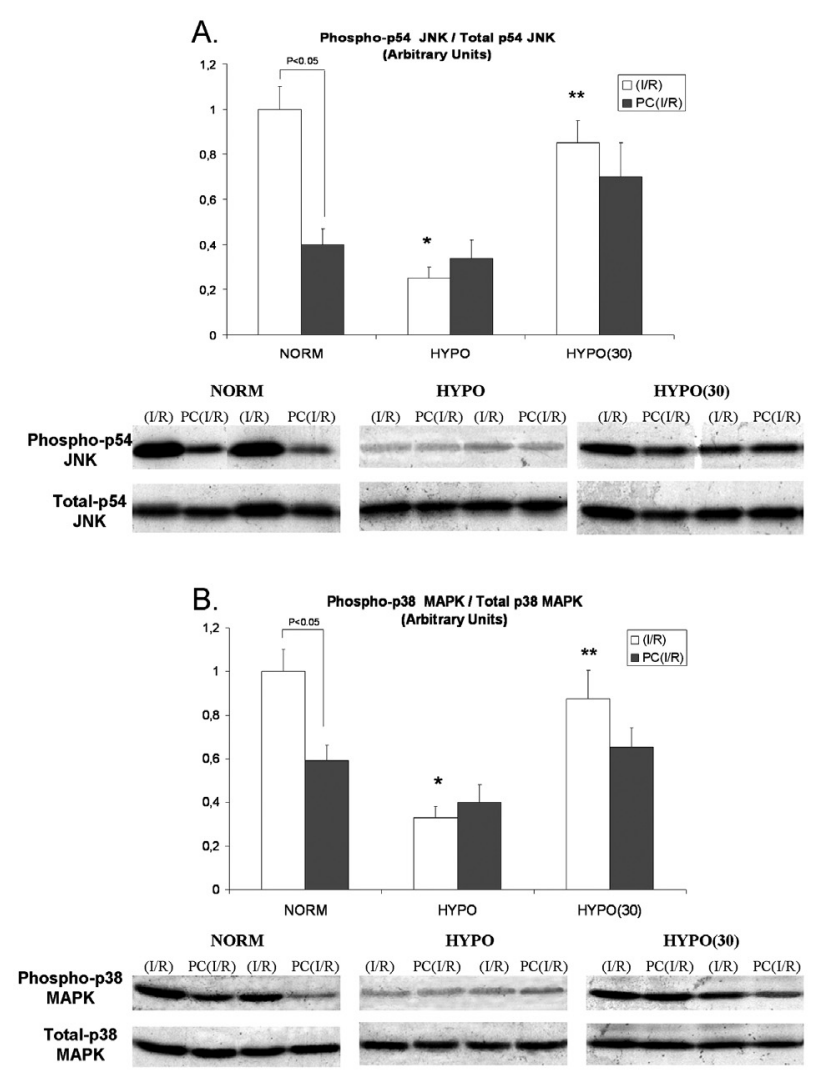

Fig. 3. Densitometric assessment in arbitrary units and representative images of $(\mathbf{A})$ the ratio of phosphorylated p54 JNK to total p54 JNK expression and (B) the ratio of phosphorylated p38 MAPK to total p38 MAPK expression in normal [NORM(I/R)], normal preconditioned [NORM-PC(I/R)], hypothyroid [HYPO(I/R)] and hypothyroid preconditioned hearts [HYPO-PC(I/R)] subjected to 20 min of ischemia and 45 min of reperfusion and hypothyroid $[\mathrm{HYPO}(30 \mathrm{I} / \mathrm{R})]$ and hypothyroid preconditioned hearts [HYPO$\mathrm{PC}(30 \mathrm{I} / \mathrm{R})$ ] subjected to $30 \mathrm{~min}$ of ischemia and $45 \mathrm{~min}$ of reperfusion. $* \mathrm{P}<0.05$ vs. $\mathrm{NORM}(\mathrm{I} / \mathrm{R}), * * \mathrm{P}<0.05$ vs. $\mathrm{HYPO}(\mathrm{I} / \mathrm{R})$

preconditioned hearts (Fig. 3).

Extending the period of ischemia to $30 \mathrm{~min}$ in hypothyroid hearts, resulted in significant increase in phosphorylated levels of $\mathrm{p} 38$ and JNK as compared to $20 \mathrm{~min}$. However, no significant reduction in the activation of those kinases was achieved in HYPO$\mathrm{PC}(30 \mathrm{I} / \mathrm{R})$ as compared to $\mathrm{HYPO}(30 \mathrm{I} / \mathrm{R})$ hearts (Fig. 3).

\section{Discussion}

Ischemic preconditioning is now thought to be a powerful means of heart protection against ischemic injury and most of the recent research is focused on its potential clinical application (Tsai et al. 2004). However, it remains largely unknown whether preconditioning is still effective when certain co-morbidities accompany the ischemic heart disease (Pantos et al. 2007a). Thus, our study has investigated whether the preconditioning response can be preserved in hypothyroidism which is a common clinical condition and predisposes to coronary artery disease (Singh et al. 2007).

In the present study, we included male Wistar rats and isolated hearts were subjected to zero-flow global ischemia followed by reperfusion, as in our previous studies (Pantos et al. 2003a,b,c,d, 2006).

The first finding of this study is that hypothyroid hearts can withstand ischemia-reperfusion injury better than normal hearts. This is in accordance with previous reports. In fact, several studies have shown that ischemic contracture is delayed and post-ischemic recovery of function is enhanced in an isolated rat heart model of ischemia-reperfusion (Abe et al. 1992, Eynan et al. 2002, Pantos et al. 2003b). Furthermore, hypothyroid hearts are shown to be protected against ischemia-reperfusion arrhythmias (Zhang et al. 2002). More importantly, lower circulating $\mathrm{T}_{3}$ levels before infarction were associated with smaller infarctions. However, after infarction these patients had worse long-term outcome (Friberg et al. 2002).

This cardioprotective effect was initially attributed to changes in metabolism and energy utilization which occurs in the hypothyroid heart. In fact, hypothyroid hearts consume less oxygen in doing mechanical work due to the predominance of the slow myosin isoform and have increased myocardial glycogen content (Abe et al. 1992, Pantos et al. 2005b). Thus, in hypothyroid hearts, ATP levels were found to decline more slowly during ischemia and be higher at reperfusion (Abe et al. 1992). Furthermore, hypothyroidism induced cardioprotection has recently been linked to changes in intracellular signaling pathway activation (Pantos et al. 2004). In fact, complex intracellular kinase signaling underlies the cellular response to stress (Baines et al. 1999, Ravingerová et al. 2003) and in experimental models of isolated perfused hearts, pro-apoptotic p38 MAPK kinase is activated during global ischemia and maintained during reperfusion, while pro-apoptotic JNKs are mainly activated at reperfusion (Bogoyevitch et al. 1996, Knight and Buxton 1996, Pantos et al. 2003c, Sato et al. 2000, Yin et al. 1997). Sustained activation of this kinase signaling appears to be detrimental and its pharmacological inhibition results in cell survival under ischemic stress (Duplain 2006, Mackay and MochlyRosen 1999). Interestingly, in the present study, we found that the phosphorylated levels of $\mathrm{p} 38$ MAPK and JNKs were significantly lower in hypothyroid hearts after 
ischemia and reperfusion as compared to control hearts, indicating a possible role of this kinase signaling in the increased tolerance of the hypothyroid heart to ischemic injury.

These data support the concept that the diseased myocardium may not always be vulnerable to ischemic injury (Pantos et al. 2007a). In fact, the diabetic heart (Hadour et al. 1998, Kristiansen et al. 2004, Wang and Chatham 2004, Xu et al. 2004), the post-infarcted myocardium (Pantos et al. 2005a, 2007b) or the hyperthyroid heart (Pantos et al. 2002, 2003d, 2006) were shown to be resistant to ischemia.

The most striking finding of the study was the differential response to ischemic preconditioning which was observed between normal and hypothyroid hearts. In fact, four-cycle preconditioning protected the normal heart against $20 \mathrm{~min}$ of no-flow global ischemia and reperfusion, but failed to confer additional protection in the hypothyroid heart. However, at this duration of ischemia, post-ischemic recovery of function was significantly higher in the hypothyroid hearts and could potentially mask the additional preconditioning effect seen in normal hearts. Thus, we subjected the hypothyroid hearts to a longer ischemic period (30 min) which resulted in comparable post-ischemic injury with that observed in the normal heart after $20 \mathrm{~min}$ of ischemia. At this duration of ischemia, preconditioning had also no additional protection. It should be noted that with longer duration of ischemia (30 min), normal hearts hardly recovered in our experimental setting. These data probably indicate that preconditioning may not be operable in hypothyroidism. However, we cannot exclude the possibility that the threshold of preconditioning stimulus may be increased in the hypothyroid heart. This issue probably merits further investigation.

The mechanisms underlying the loss of preconditioning response in the hypothyroid hearts remain largely unknown. In the non-diseased myocardium, we and other investigators have shown that ischemic preconditioning or heat preconditioning can protect the healthy myocardium by lowering the sustained activation of the pro-apoptotic p38 MAPK and JNKs kinase signaling during the subsequent ischemia and reperfusion phase (Marais et al. 2001, Pantos et al. 2002, 2003a). Similarly, in the present study, ischemiareperfusion induced p38 MAPK and JNKs activation (as assessed by the phosphorylated levels of these kinases) was found to be significantly reduced in preconditioned normal as compared to non-preconditioned hearts. However, preconditioning did not further attenuate the activation of this signaling in the hypothyroid hearts, partly explaining the failure of preconditioning to confer added protection in those hearts against ischemia and reperfusion injury .

The present study has provided additional evidence supporting the notion that the diseased myocardium may lose the ability to be preconditioned (Pantos et al. 2007a). This needs to be taken into account before translating preconditioning research to therapeutic application in humans. In fact, in clinical practice, coronary artery disease may co-exist with other morbidities which can potentially modify the response of the myocardium to ischemic stress.

In conclusion, hypothyroid hearts are tolerant to ischemia-reperfusion injury, partly due to the downregulation of the ischemia-reperfusion induced activation of JNKs and p38 MAPK kinase signaling pathways. Ischemic preconditioning is not associated with further reduction in the activation of these kinases and fails to confer added protection in those hearts.

\section{Conflict of Interest}

There is no conflict of interest.

\section{Acknowledgements}

"Kavalis" and "Fragopoulos" foundation as well as "ELETRON" supported this work.

\section{References}

ABE M, OBATA H, TANAKA H: Functional and metabolic responses to ischemia in the isolated perfused hypothyroid rat heart. Jpn Circ J 56: 671-680, 1992.

BAINES CP, COHEN MV, DOWNEY JM: Signal transduction in ischemic preconditioning: the role of kinases and mitochondrial $\mathrm{K}_{\mathrm{ATP}}$ channels. J Cardiovasc Electrophysiol 10: 741-754, 1999. 
BOGOYEVITCH MA, GILLESPIE-BROWN J, KETTERMAN AJ, FULLER SJ, BEN-LEVY R, ASHWORTH A, MARSHALL CJ, SUGDEN PH: Stimulation of the stress-activated mitogen-activated protein kinase subfamilies in perfused heart. p38/RK mitogen-activated protein kinases and c-Jun N-terminal kinases are activated by ischemia/reperfusion. Circ Res 79: 162-173, 1996.

DAS DK, MAULIK N: Cardiac genomic response following preconditioning stimulus. Cardiovasc Res 70: 254-263, 2006.

DUPLAIN H: Salvage of ischemic myocardium: a focus on JNK. Adv Exp Med Biol 588: 157-164, 2006.

EYNAN M, KNUBUVETZ T, MEIRI U, NAVON G, GERSTENBLITH G, BROMBERG Z, HASIN Y, HOROWITZ M: Heat acclimation-induced elevated glycogen, glycolysis, and low thyroxine improve heart ischemic tolerance. J Appl Physiol 93: 2095-2104, 2002.

FRIBERG L, WERNER S, EGGERTSEN G, AHNVE S: Rapid down-regulation of thyroid hormones in acute myocardial infarction: is it cardioprotective in patients with angina? Arch Intern Med 162: 1388-1394, 2002.

HADOUR G, FERRERA R, SEBBAG L, FORRAT R, DELAYE J, DE LORGERIL M: Improved myocardial tolerance to ischaemia in the diabetic rabbit. J Mol Cell Cardiol 30: 1869-1875, 1998.

IERVASI G, PINGITORE A, LANDI P, RACITI M, RIPOLI A, SCARLATTINI M, L'ABBATE A, DONATO L: Low- $\mathrm{T}_{3}$ syndrome: a strong prognostic predictor of death in patients with heart disease. Circulation 107: 708$713,2003$.

KNIGHT RJ, BUXTON DB: Stimulation of c-Jun kinase and mitogen-activated protein kinase by ischemia and reperfusion in the perfused rat heart. Biochem Biophys Res Commun 218: 83-88, 1996.

KONERU S, PENUMATHSA SV, THIRUNAVUKKARASU M, SAMUEL SM, ZHAN L, HAN Z, MAULIK G, DAS DK, MAULIK N: Redox regulation of ischemic preconditioning is mediated by the differential activation of caveolins and their association with eNOS and GLUT-4. Am J Physiol 292: H2060-H2072, 2007.

KRISTIANSEN SB, LOFGREN B, STOTTRUP NB, KHATIR D, NIELSEN-KUDSK JE, NIELSEN TT, BOTKER HE, FLYVBJERG A: Ischaemic preconditioning does not protect the heart in obese and lean animal models of type 2 diabetes. Diabetologia 47: 1716-1721, 2004.

MACKAY K, MOCHLY-ROSEN D: An inhibitor of p38 mitogen-activated protein kinase protects neonatal cardiac myocytes from ischemia. J Biol Chem 274: 6272-6279, 1999.

MARAIS E, GENADE S, HUISAMEN B, STRIJDOM JG, MOOLMAN JA, LOCHNER A: Activation of p38 MAPK induced by a multi-cycle ischaemic preconditioning protocol is associated with attenuated p38 MAPK activity during sustained ischaemia and reperfusion. J Mol Cell Cardiol 33: 769-778, 2001.

PANTOS CI, COKKINOS DD, TZEIS SM, MALLIOPOULOU V, MOUROUZIS IS, CARAGEORGIOU HC, LIMAS C, VARONOS DV, COKKINOS DV: Hyperthyroidism is associated with preserved preconditioning capacity but intensified and accelerated ischaemic contracture in rat heart. Basic Res Cardiol 94: 254-260, 1999.

PANTOS CI, MALLIOPOULOU VA, MOUROUZIS IS, KARAMANOLI EP, PAIZIS IA, STEIMBERG N, VARONOS DD, COKKINOS DV: Long-term thyroxine administration protects the heart in a pattern similar to ischemic preconditioning. Thyroid 12: 325-329, 2002.

PANTOS C, MALLIOPOULOU V, MOUROUZIS I, MORAITIS P, TZEIS S, THEMPEYIOTI A, PAIZIS I, COKKINOS A, CARAGEORGIOU H, VARONOS DD, COKKINOS DV: Involvement of p38 MAPK and JNK in heat stress-induced cardioprotection. Basic Res Cardiol 98: 158-164, 2003a.

PANTOS C, MALLIOPOULOU V, MOUROUZIS I, SFAKIANOUDIS K, TZEIS S, DOUMBA P, XINARIS C, COKKINOS AD, CARAGEORGIOU H, VARONOS DD, COKKINOS DV: Propylthiouracil-induced hypothyroidism is associated with increased tolerance of the isolated rat heart to ischaemia-reperfusion. $J$ Endocrinol 178: 427-435, 2003b.

PANTOS C, MALLIOPOULOU V, PAIZIS I, MORAITIS P, MOUROUZIS I, TZEIS S, KARAMANOLI E, COKKINOS DD, CARAGEORGIOU H, VARONOS D, COKKINOS DV: Thyroid hormone and cardioprotection: study of $\mathrm{p} 38$ MAPK and JNKs during ischaemia and at reperfusion in isolated rat heart. $\mathrm{Mol}$ Cell Biochem 242: 173-180, 2003c. 
PANTOS C, MALLIOPOULOU V, MOUROUZIS I, KARAMANOLI E, MORAITIS P, TZEIS S, PAIZIS I, COKKINOS AD, CARAGEORGIOU H, VARONOS DD, COKKINOS DV: Thyroxine pretreatment increases basal myocardial heat-shock protein 27 expression and accelerates translocation and phosphorylation of this protein upon ischaemia. Eur J Pharmacol 478: 53-60, $2003 \mathrm{~d}$.

PANTOS C, MALLIOPOULOU V, VARONOS DD, COKKINOS DV: Thyroid hormone and phenotypes of cardioprotection. Basic Res Cardiol 99: 101-120, 2004.

PANTOS C, MOUROUZIS I, SARANTEAS T, PAIZIS I, XINARIS C, MALLIOPOULOU V, COKKINOS DV: Thyroid hormone receptors alphal and betal are downregulated in the post-infarcted rat heart: consequences on the response to ischaemia-reperfusion. Basic Res Cardiol 100: 422-432, 2005a.

PANTOS C, MOUROUZIS I, MALLIOPOULOU V, PAIZIS I, TZEIS S, MORAITIS P, SFAKIANOUDIS K, VARONOS DD, COKKINOS DV: Dronedarone administration prevents body weight gain and increases tolerance of the heart to ischemic stress: a possible involvement of thyroid hormone receptor alpha1. Thyroid 15: 16-23, 2005b.

PANTOS C, MALLIOPOULOU V, MOUROUZIS I, THEMPEYIOTI A, PAIZIS I, DIMOPOULOS A, SARANTEAS T, XINARIS C, COKKINOS DV: Hyperthyroid hearts display a phenotype of cardioprotection against ischemic stress: a possible involvement of heat shock protein 70. Horm Metab Res 38: 308-313, 2006.

PANTOS C, MOUROUZIS I, COKKINOS DV: Protection of the abnormal heart. Heart Fail Rev 12: 319-330, 2007a.

PANTOS C, MOUROUZIS I, DIMOPOULOS A, MARKAKIS K, PANAGIOTOU M, XINARIS C, TZEIS S, KOKKINOS AD, COKKINOS DV: Enhanced tolerance of the rat myocardium to ischemia and reperfusion injury early after acute myocardial infarction. Basic Res Cardiol 102: 327-333, 2007b.

PANTOS C, DRITSAS A, MOUROUZIS I, DIMOPOULOS A, KARATASAKIS G, ATHANASSOPOULOS G, MAVROGENI S, MANGINAS A, COKKINOS DV: Thyroid hormone is a critical determinant of myocardial performance in patients with heart failure: potential therapeutic implications. Eur J Endocrinol 157: 515-520, 2007c.

PANTOS C, MOUROUZIS I, XINARIS C, KOKKINOS AD, MARKAKIS K, DIMOPOULOS A, PANAGIOTOU M, SARANTEAS T, KOSTOPANAGIOTOU G, COKKINOS DV: Time-dependent changes in the expression of thyroid hormone receptor alpha 1 in the myocardium after acute myocardial infarction: possible implications in cardiac remodelling. Eur J Endocrinol 156: 415-424, 2007d.

RAVINGEROVÁ T, BARANČÍK M, STRNISKOVÁ M: Mitogen-activated protein kinases: a new therapeutic target in cardiac pathology. Mol Cell Biochem 247: 127-138, 2003.

REISER PJ, KLINE WO: Electrophoretic separation and quantitation of cardiac myosin heavy chain isoforms in eight mammalian species. Am J Physiol 274: H1048-H1053, 1998.

SATO M, CORDIS GA, MAULIK N, DAS DK: SAPKs regulation of ischemic preconditioning. Am J Physiol 279: H901-H907, 2000.

SINGH S, DUGGAL J, MOLNAR J, MALDONADO F, BARSANO CP, ARORA R: Impact of subclinical thyroid disorders on coronary heart disease, cardiovascular and all-cause mortality: a meta-analysis. Int J Cardiol 2007.

TSAI BM, WANG M, MARCH KL, TURRENTINE MW, BROWN JW, MELDRUM DR: Preconditioning: evolution of basic mechanisms to potential therapeutic strategies. Shock 21: 195-209, 2004.

VALEN G: Cellular signalling mechanisms in adaptation to ischemia-induced myocardial damage. Ann Med 35: 300$307,2003$.

WANG P, CHATHAM JC: Onset of diabetes in Zucker diabetic fatty (ZDF) rats leads to improved recovery of function after ischemia in the isolated perfused heart. Am J Physiol 286: E725-E736, 2004.

XU G, TAKASHI E, KUDO M, ISHIWATA T, NAITO Z: Contradictory effects of short- and long-term hyperglycemias on ischemic injury of myocardium via intracellular signaling pathway. Exp Mol Pathol 76: 57$65,2004$. 
YIN T, SANDHU G, WOLFGANG CD, BURRIER A, WEBB RL, RIGEL DF, HAI T, WHELAN J: Tissue-specific pattern of stress kinase activation in ischemic/reperfused heart and kidney. J Biol Chem 272: 19943-19950, 1997.

ZHANG L, PARRATT JR, BEASTALL GH, PYNE NJ, FURMAN BL: Streptozotocin diabetes protects against arrhythmias in rat isolated hearts: role of hypothyroidism. Eur J Pharmacol 435: 269-276, 2002. 